\title{
Polymorphisms in the 5-Hydroxytryptamine 2A Receptor and CytochromeP4502D6 Genes Synergistically Predict Fluvoxamine-Induced Side Effects in Japanese Depressed Patients
}

\author{
Yutaro Suzuki', Kazushi Sawamura' and Toshiyuki Someya*,' \\ 'Department of Psychiatry, Niigata University Graduate School of Medical and Dental Sciences, Niigata, Japan
}

\begin{abstract}
5-Hydroxytryptamine (5-HT) receptors are thought to be associated with the gastrointestinal side effects induced by selective serotonin reuptake inhibitors. CytochromeP450 (CYP) 2D6 may also be associated with the side effects induced by fluvoxamine, since the plasma fluvoxamine concentration depends on a CYP2D6 gene polymorphism. This study investigated whether 5-HT receptor and CYP2D6 gene polymorphisms could predict the occurrence of the side effects. The effects of 5-HT receptor and CYP2D6 gene polymorphisms on the incidence of gastrointestinal side effects induced by fluvoxamine were investigated in 100 depressed outpatients who gave written consent to participate in the study. The patients visited every 2 weeks until the week 12 end point and the fluvoxamine dose was changed in response to their clinical symptoms. All side effects, including the gastrointestinal side effects, were assessed at each visit. Polymerase chain reaction was used to determine A-1438G of the 5-HT2A receptor, C195T and Prol6Ser of the 5-HT3A receptor, Tyr I29Ser of the 5-HT3B receptor, and the *5 and * 10 alleles of CYP2D6. Both the A- I438G polymorphism of the 5-HT2A receptor gene and the CYP2D6 gene polymorphism had significant effects on the incidence of gastrointestinal side effects. Cox regression was used to analyze the combination effect of the two polymorphisms on the gastrointestinal side effects. Cox regression analysis showed that lower metabolizers (LMs) of CYP2D6 with the G/G genotype of the 5-HT2A A-I 438G polymorphism had a 4.242-fold ( $P=0.009$ ) and LMs with the A/G genotype had a 4.147-fold $(P=0.004)$ higher risk of developing gastrointestinal side effects than normal metabolizers with the A/A genotype. The 5-HT3A and 3B gene polymorphisms had no significant effects on the incidence of gastrointestinal side effects. 5-HT2A receptor and CYP2D6 gene polymorphisms had a synergistic effect for the prediction of fluvoxamine-induced gastrointestinal side effects.
\end{abstract}

Neuropsychopharmacology (2006) 31, 825-831. doi:I0.1038/sj.npp. I300919; published online 5 October 2005

Keywords: cytochromeP4502D6; fluvoxamine; side effects; 5-HT2A; genetic polymorphism

\section{INTRODUCTION}

Fluvoxamine is widely available in Europe and the United States, and was introduced into clinical use as the first approved selective serotonin (5-hydroxytryptamine (5-HT)) reuptake inhibitor (SSRI) in Japan in 1999. Although SSRIs, including fluvoxamine, are known to have fewer side effects than tricyclic antidepressants (TCAs), the side-effect profiles of SSRIs and TCAs are different (Trindade et al, 1998). While TCAs have been reported to cause anti-

\footnotetext{
*Correspondence: Dr T Someya, Department of Psychiatry, Niigata University Graduate School of Medical and Dental Sciences, 757 Asahimachidori-ichibancho, Niigata 95I-85I0, Japan, Tel: +8I 25227 22।3, Fax: + 8I 25227 0777, E-mail: someya@med.niigata-u.ac.jp Received 29 March 2005; revised 26 July 2005; accepted II August 2005

Online publication: I September 2005 at http://www.acnp.org/citations/ Npp090 105050208/default.pdf
}

cholinergic side effects, including a dry mouth, constipation, blurred vision, urinary retention, and postural hypotension, SSRIs are associated with gastrointestinal side effects, including nausea, vomiting, stomach ache, and diarrhea. In general, SSRIs are better tolerated than TCAs, although the gastrointestinal side effects have an incidence of up to $40 \%$ (Kasper et al, 1992; Trindade et al, 1998) and can be severe enough to lead to early treatment discontinuation (Kasper et al, 1992; Trindade et al, 1998; Murphy et al, 2003).

Recently, 5-HT3 receptors have been considered to have important roles in SSRI-induced gastrointestinal side effects, since the 5-HT3 receptor antagonists cisapride and ondansetron were reported to reduce the gastrointestinal side effects induced by SSRIs (Bergeron and Blier, 1994). Some variations in the 5-HT3A and 5-HT3B receptor genes have been detected (Tremblay et al, 2003; Kaiser et al, 2004), and Tremblay et al (2003) reported that variations in the 
5-HT3B receptor gene predicted the efficacy of antiemetic treatment in cancer patients. However, no previous studies have investigated the effects of 5-HT3A and 5-HT3B receptor gene polymorphisms on the occurrence of gastrointestinal side effects induced by SSRIs.

Furthermore, since peripheral 5-HT2A receptors are associated with gut motility and vascular smooth muscle tone (Banes et al, 1999; Janssen et al, 2002), polymorphisms of the 5-HT2A receptor gene may affect the gastrointestinal side effects induced by SSRIs. Murphy et al (2003) reported that the $\mathrm{T} 102 \mathrm{C}$ polymorphism of the 5-HT2A receptor gene could predict the treatment discontinuation caused by paroxetine-induced side effects in depressed elderly patients. However, since elderly patients are considered to have different pharmacodynamic and pharmacokinetic profiles from younger patients, it is necessary to investigate whether the results in Murphy et al (2003) are consistent with those for other depressed patients.

Kasper et al (1992) reported that an increased incidence of nausea was associated with higher plasma concentrations of fluvoxamine. CytochromeP450 (CYP) 2D6 has been shown to be involved in the metabolism of fluvoxamine, and CYP2D6 is known to have genetic polymorphisms that affect the enzyme activity (Greenblatt et al, 1998; http:// www.imm.ki.se/CYPalleles/). These observations suggest that the polymorphic CYP2D6 may be a predictor for fluvoxamine-induced side effects. On the other hand, Hartter et al (1998) reported that there was no relationship between the serum concentration of fluvoxamine and the side effects. Gerstenberg et al (2003) reported that steady-state plasma concentrations of fluvoxamine were not associated with the incidence of nausea, and that the CYP2D6 genotypes did not affect nausea development. Further studies are needed to clarify whether the CYP2D6 gene polymorphisms affect fluvoxamine-induced side effects.

In this study, we investigated the effects of pharmacodynamic factors, such as 5-HT2A, 5-HT3A, and 5-HT3B receptor gene polymorphisms, and pharmacokinetic factors, such as CYP2D6 genotypes, on the occurrence of gastrointestinal side effects induced by fluvoxamine in Japanese depressed patients.

\section{MATERIALS AND METHODS}

\section{Subjects}

This study was conducted at the Niigata University Medical Hospital. The study protocol was approved by the Ethics Committee of Niigata University Medical Hospital, and each subject provided written informed consent before enrolment. The subjects comprised 100 Japanese depressed outpatients (47 men, 53 women) aged $40.5 \pm 15.7$ years (mean age $\pm S D)$. In all, 85 subjects had DSM-IV diagnoses of major depressive disorder, seven had adjustment disorder with depressed mood, six had a depressive disorder not otherwise specified, and two had bipolar I disorder in a depressed state. The exclusion criteria were additional diagnoses of Axis I or II of DSM-IV. All the patients had been free from psychotropic drugs for at least 14 days before their entry into the study. Demographic data, medical histories, and laboratory data, including hemato- logy, serology, electrolytes, and urine analysis, were collected for each patient. Patients with obvious physical illnesses were excluded from the study. All patients were orally treated with fluvoxamine for their psychiatric illnesses.

\section{Study Design}

On the first examination (week 0), after informed consent was obtained, the symptoms of the patients were evaluated by the 17-item Hamilton Rating Scale for Depression (HAM-D-17) and they were treated with fluvoxamine at a starting dose of $25 \mathrm{mg} /$ day for the first week. The patients subsequently visited at weeks $1,2,4,6,8,10$, and 12 after the first examination. The HAM-D-17 score and all side effects, including the gastrointestinal side effects, were assessed at each visit. If the improvement rate in the HAMD-17 score was less than $40 \%$ compared with the score on the previous visit, the fluvoxamine dose was increased from 25 to $50 \mathrm{mg} / \mathrm{day}$, and subsequently to 100,150 , and $200 \mathrm{mg} /$ day if necessary. When the patients achieved remission (a HAM-D-17 score of less than 8 points), the fluvoxamine dose was not subsequently changed. Side effects were evaluated by our original rating scale, including 13 items as follows: nausea, vomiting, dry mouth, anorexia, constipation, diarrhea, stomachache, sleepiness, irritable mood, anxiety, insomnia, headache, and dizziness. Subjects were interviewed about the 13 items at each visit and the severity of each item was evaluated according to the two-grade ( 0 or 1$)$ system. Gastrointestinal side effects consisted of five items: nausea, vomiting, anorexia, diarrhea, and stomachache. As gastrointestinal symptoms are not only side effects, but also symptoms of major depression, the gastrointestinal symptoms were not evaluated as side effects when the item 'gastrointestinal symptoms' of HAM-D-17 score become worse compared with the last visit.

\section{Data Collection}

Blood sampling was performed using a Venoject ${ }^{\circledR}$ tube containing EDTA-Na (Terumo Japan, Tokyo, Japan) at week 1 for genotype detection, and subsequently at the first appearance of gastrointestinal side effects to measure the concentration of fluvoxamine. Blood samples were also taken at $12 \mathrm{~h}$ after the final ingestion of fluvoxamine. In all, $7 \mathrm{ml}$ of venous blood was collected, and genomic DNA was extracted from the peripheral leukocytes by utilizing a QIAamp Blood Kit (QIAGEN Inc., CA, USA) within $2 \mathrm{~h}$ of collection. Polymerase chain reaction (PCR) was used to determine the A-1438G genotype of the 5-HT2A receptor gene according to Erdmann et al (1996), the C195T and Pro16Ser genotypes of the 5-HT3A receptor gene according to Niesler et al (2001), and the Tyr129Ser genotype of the 5-HT3B receptor gene according to Tremblay et al (2003).

CYP2D6*10 alleles causing decreased enzyme activity were identified by the C188T mutation using a two-step PCR analysis as described (Johansson et al, 1994). A longPCR analysis was used to detect the ${ }^{\star} 5$ allele causing a lack of enzyme activity as described (Steen et al, 1995).

The plasma concentration of fluvoxamine was measured using a column-switching high-performance liquid chromatography method with ultraviolet detection. The drug in 
plasma, to which cisapride had been added as an internal standard, was extracted with hexane-chloroform, and the extract was subjected to automated column-switching highperformance liquid chromatography using a TSK BSA-C8 precolumn (Tosoh, Tokyo, Japan) for sample clean-up, and a TSK gel ODS-80TS column (Tosoh) for separation.

\section{Statistical Analysis}

Kaplan-Meier survival analysis and Cox regression analysis were used to compare the probabilities of the incidence of side effects. Genotype and allele distributions were analyzed by the $\chi^{2}$-test. The clinical and demographic characteristics, onset weeks, onset doses, onset concentrations, and cumulative numbers of side effects were compared among groups by the unpaired $t$-test or one-way analysis of variance. The level of significance was set at less than 0.05 .

\section{RESULTS}

The genotype frequencies of the 5-HT2A, 5-HT3A, and 5 -HT3B genes are shown in Tables 1,2 and 3. All of these genetic variations were in Hardy-Weinberg equilibrium. The genotypes of the 5-HT3A C195T polymorphism were not detected in seven patients. The other three genotypes of four patients could not be identified. No significant differences were demonstrated for sex, age, and baseline HAM-D-17 scores among the genotype groups.

\section{Effect of the 5-HT2A Gene A-1438G Polymorphism}

The cumulative incidences of fluvoxamine-induced gastrointestinal side effects are presented in Figure 1. Cox regression was used to analyze the effect of the 5-HT2A gene A-1438G polymorphism on the gastrointestinal side effects. The number of $G$ alleles was entered into the analysis as an independent variable, and sex, age, and baseline HAM-D-17 score were added as potential confounders. The Cox regression analysis showed that patients with one $\mathrm{G}$ allele had a 2.171-fold higher risk of developing gastrointestinal side effects $(P=0.041 ; 95 \%$ confidence interval (CI), 1.032-4.566) and patients with two G alleles had a 2.926-fold higher risk of developing gastrointestinal side effects $(P=0.008 ; 95 \% \mathrm{CI}, 1.321-6.481)$ than patients with no $G$ allele. Sex, age, and baseline HAM-D-17 scores showed no significant effects on the risk of developing gastrointestinal side effects. There were no significant differences in the incidence of discontinuation between the three genotype groups $\left(\chi^{2}=0.029, \mathrm{df}=2, P=0.986\right)$ (Table 1).

Significant trends were demonstrated for the cumulative number of gastrointestinal side effects between the three genotype groups, although no significant differences were observed for the onset weeks, onset doses, and onset concentrations of fluvoxamine.

On the other hand, survival analyses showed no significant effect of the A-1438G polymorphism on the onset rate of all side effects, including the gastrointestinal side effects. No significant differences were demonstrated for the onset weeks, onset doses, onset concentrations, and cumulative numbers of all side effects between the genotype groups (Table 1).
Table I Characteristics of the Demographic Data and Fluvoxamine-Induced Side Effects by Comparison of the A-I438G Genotypes of the 5-HT2A Receptor

\begin{tabular}{|c|c|c|c|}
\hline & \multicolumn{3}{|c|}{$\begin{array}{c}\text { 5-HT2A gene A-I438G } \\
\text { polymorphism }^{\mathrm{a}}\end{array}$} \\
\hline & $\begin{array}{c}\text { A/A } \\
(\mathbf{N}=\mathbf{2 8})\end{array}$ & $\begin{array}{c}\text { A/G } \\
(N=4 I)\end{array}$ & $\begin{array}{c}\mathbf{G} / \mathbf{G} \\
(N=27)\end{array}$ \\
\hline $\operatorname{Sex}(M / F)$ & $12 / 16$ & $24 / 17$ & $11 / 16$ \\
\hline Age & $40.8(17.6)$ & $41.3(15.4)$ & $38.2(14.7)$ \\
\hline Baseline HAM-D- 17 score & $21.6(5.2)$ & $20.2(5.4)$ & $20.0(4.9)$ \\
\hline Discontinuation & 7 & 11 & 7 \\
\hline$P$ & & 0.986 & \\
\hline \multicolumn{4}{|l|}{ Gastrointestinal side effects } \\
\hline Number of patients & 10 & 25 & 18 \\
\hline Onset week & $3.4(2.9)$ & $3.9(2.7)$ & $2.1(2.0)$ \\
\hline$P$ & & 0.073 & \\
\hline Onset dose (mg) & $60.0(42.8)$ & $75.0(53.5)$ & $45.8(43.9)$ \\
\hline$P$ & & 0.16 & \\
\hline Onset concentration $(\mathrm{ng} / \mathrm{ml})$ & $46.5(70.3)$ & $25.0(27.8)$ & $24.6(32.9)$ \\
\hline P & & 0.366 & \\
\hline $\begin{array}{l}\text { Cumulative number of side } \\
\text { effects }\end{array}$ & $0.7(1.2)$ & $1.7(2.0)$ & $2.0(2.7)$ \\
\hline$P$ & & 0.05 & \\
\hline \multicolumn{4}{|l|}{ All side effects } \\
\hline Number of patients & 21 & 34 & 22 \\
\hline Onset week & $3.2(2.9)$ & $3.1(2.8)$ & $1.9(1.7)$ \\
\hline$P$ & & 0.139 & \\
\hline Onset dose (mg) & $56.0(31.5)$ & $62.5(47.8)$ & $39.8(24.0)$ \\
\hline$P$ & & 0.097 & \\
\hline $\begin{array}{l}\text { Cumulative number of } \\
\text { side effects }\end{array}$ & $2.8(3.3)$ & $5.3(6.7)$ & $5.0(4.6)$ \\
\hline$P$ & & 0.147 & \\
\hline
\end{tabular}

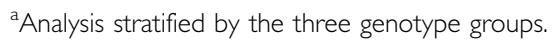

5-HT = 5-hydroxytryptamine; HAM-D-17 = 17-item Hamilton Rating Scale for Depression.

\section{Effects of the 5-HT3A and 5-HT3B Gene Polymorphisms}

Although Cox regression analysis was performed to investigate the effects of Pro16Ser and C195T of the 5-HT3A gene and Tyr129Ser of the 5-HT3B gene on the gastrointestinal side effects or all side effects, these polymorphisms had no significant effects on the occurrence of fluvoxamine-induced side effects (Tables 2 and 3). No significant differences were demonstrated for the onset weeks and doses of gastrointestinal side effects or all side effects in each genotype group.

\section{Effect of the CYP2D6 Gene Polymorphism}

The allele frequencies of the $\star_{5}$ and ${ }^{\star} 10$ alleles were 3.6 and $38.1 \%$, respectively. The patients were divided into two genotype groups by the degree of enzyme activity: 75 
Table 2 Characteristics of the Demographic Data and Fluvoxamine-Induced Side Effects by Comparison of the 5-HT3A Receptor Gene Polymorphisms

\begin{tabular}{|c|c|c|c|c|c|c|}
\hline & \multicolumn{6}{|c|}{ 5-HT3A gene } \\
\hline & \multicolumn{3}{|c|}{ Prol6Ser } & \multicolumn{3}{|c|}{ C195T } \\
\hline $\operatorname{Sex}(M / F)$ & $38 / 38$ & $9 / 9$ & $0 / 2$ & $2 / 6$ & $18 / 17$ & $25 / 25$ \\
\hline Age & $41.2(15.5)$ & $39.1(16.2)$ & $17.0(5.7)$ & $29.3(15.5)$ & $38.5(13.3)$ & $43.5(16.6)$ \\
\hline \multicolumn{7}{|l|}{ Gastrointestinal side effects } \\
\hline Number of patients & 44 & 7 & 2 & 5 & 19 & 26 \\
\hline \multicolumn{7}{|l|}{ All side effects } \\
\hline
\end{tabular}

5-HT = 5-hydroxytryptamine; HAM-D-17 = 17-item Hamilton Rating Scale for Depression.

Table 3 Characteristics of the Demographic Data and Fluvoxamine-Induced Side Effects by Comparison of the 5-HT3B Receptor Gene Polymorphisms

\section{5-HT3B gene}

\begin{tabular}{lccc}
\cline { 2 - 4 } & \multicolumn{3}{c}{ Tyrl29Ser } \\
\cline { 2 - 4 } & $\begin{array}{l}\text { Tyr/Tyr } \\
\mathbf{( N = 5 4 )}\end{array}$ & $\begin{array}{c}\text { Tyr/Ser } \\
\mathbf{( N = 3 7 )}\end{array}$ & $\begin{array}{c}\text { Ser/Ser } \\
(\mathbf{N}=\mathbf{5})\end{array}$ \\
\hline Sex (M/F) & $29 / 25$ & $17 / 20$ & $1 / 4$ \\
Age & $40.2(16.6)$ & $39.8(15.4)$ & $44.4(9.9)$ \\
Baseline HAM-D-17 score & $21.2(5.2)$ & $20.1(5.3)$ & $17.2(4.3)$ \\
Gastrointestinal side effects & & & \\
$\quad$ Number of patients & 28 & 22 & 3 \\
All side effects & & & 5 \\
Number of patients & 42 & 30 & \\
\hline
\end{tabular}

5-HT = 5-hydroxytryptamine; HAM-D-17 = 17-item Hamilton Rating Scale for Depression.

patients with the ${ }^{\star} 1 /^{\star} 1$ or ${ }^{\star} 1 /^{\star} 10$ genotype were termed normal metabolizers (NMs), and 22 patients with the ${ }^{\star} 10 /{ }^{\star} 10,{ }^{\star} 1 /^{\star} 5$ or ${ }^{\star} 5 /{ }^{\star} 10$ genotype were termed lower metabolizers (LMs) (Table 4). Figure 2 shows the effect of the CYP2D6 polymorphism on the incidence of gastrointestinal side effects. Cox regression analysis showed that LMs of CYP2D6 had a significantly higher risk of developing gastrointestinal side effects than NMs $(P=0.043$; hazard ratio (HR), $1.821 ; 95 \% \mathrm{CI}, 1.019-3.254$ ).

There were no significant differences in the incidence of discontinuation between NMs and LMs $\left(\chi^{2}=1.029, \mathrm{df}=1\right.$, $P=0.310)$. No significant differences were demonstrated for the onset weeks, onset doses, onset concentrations, and cumulative numbers of gastrointestinal side effects or all side effects between NMs and LMs (Table 4).

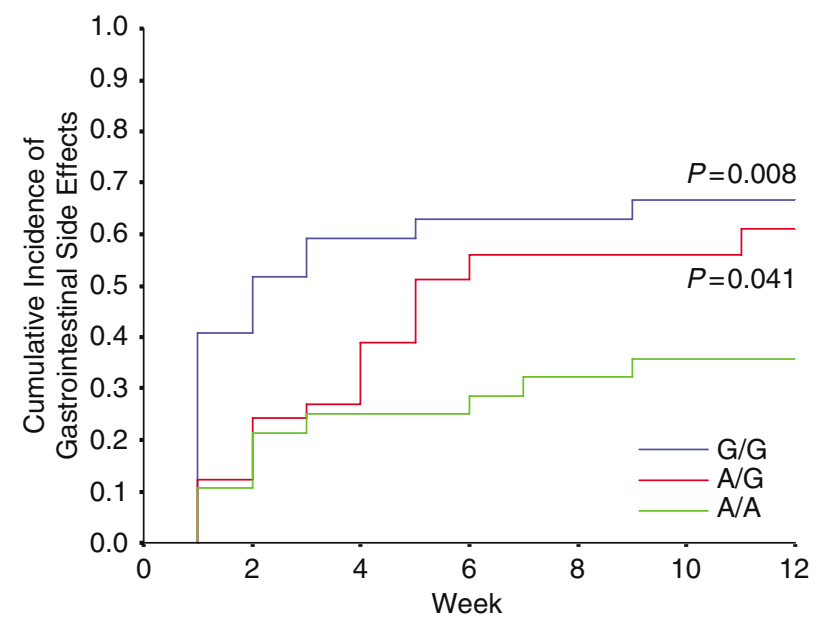

Figure I Effect of the A-I438G polymorphism of the 5-HT2A receptor gene on the cumulative 12-week incidence of gastrointestinal side effects induced by fluvoxamine.

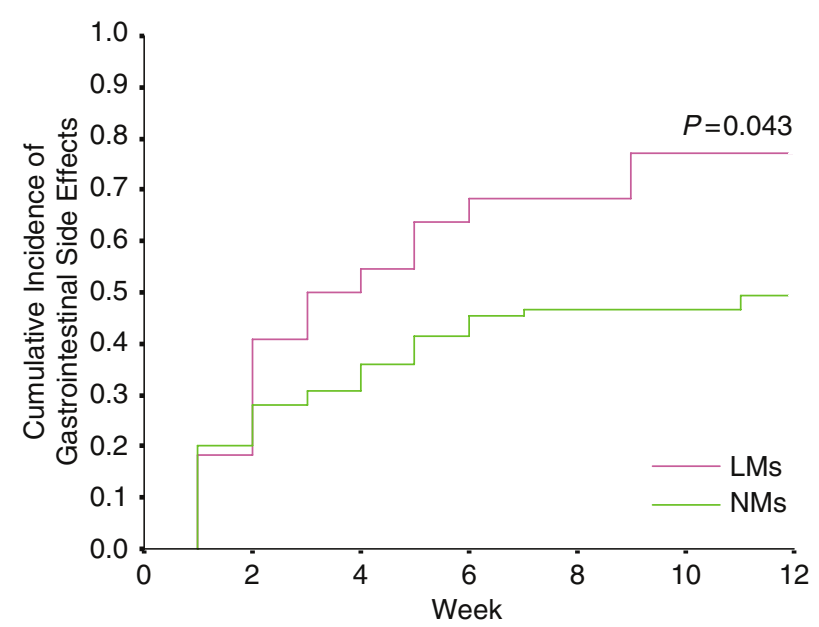

Figure 2 Effect of the CYP2D6 genotype on the cumulative 12-week incidence of gastrointestinal side effects induced by fluvoxamine. 
Table 4 Characteristics of the Demographic Data and Fluvoxamine-Induced Side Effects by Comparison of the CYP2D6 Genotype Groups

\begin{tabular}{|c|c|c|}
\hline & \multicolumn{2}{|c|}{ CYP2D6 genotype (phenotype) $^{a}$} \\
\hline & $\begin{array}{c}* I / * I, * I / * 10 \\
(\mathbf{N M s}) \\
(\mathbf{N}=\mathbf{7 5})\end{array}$ & $\begin{array}{c}* I / F, * I 0 / * 10, * 5 / * I 0 \\
(\mathrm{LMs}) \\
(\mathrm{N}=22)\end{array}$ \\
\hline $\operatorname{Sex}(M / F)$ & $35 / 40$ & $12 / 10$ \\
\hline Age & $39.1(16.1)$ & $43.8(14.2)$ \\
\hline Baseline HAM-D-I7 score & $20.3(5.3)$ & $21.4(5.0)$ \\
\hline Discontinuation & 17 & 8 \\
\hline$P$ & \multicolumn{2}{|c|}{0.267} \\
\hline \multicolumn{3}{|l|}{ Gastrointestinal side effects } \\
\hline Number of patients & 37 & 17 \\
\hline Onset week & $3.1(2.7)$ & $3.4(2.6)$ \\
\hline$P$ & \multicolumn{2}{|c|}{0.723} \\
\hline Onset dose (mg) & $64.9(50.5)$ & $58.8(47.6)$ \\
\hline$P$ & \multicolumn{2}{|c|}{0.679} \\
\hline $\begin{array}{l}\text { Onset concentration } \\
(\mathrm{ng} / \mathrm{ml})\end{array}$ & $29.7(44.8)$ & $27.4(30.3)$ \\
\hline$P$ & \multicolumn{2}{|c|}{0.855} \\
\hline $\begin{array}{l}\text { Cumulative number } \\
\text { of side effects }\end{array}$ & $2.7(2.3)$ & $2.8(1.9)$ \\
\hline$P$ & & 49 \\
\hline \multicolumn{3}{|l|}{ All side effects } \\
\hline Number of patients & 58 & 20 \\
\hline Onset week & $2.7(2.4)$ & $3.3(3.2)$ \\
\hline$P$ & \multicolumn{2}{|c|}{0.357} \\
\hline Onset dose (mg) & $56.0(37.3)$ & $51.3(44.0)$ \\
\hline$P$ & \multicolumn{2}{|c|}{0.638} \\
\hline $\begin{array}{l}\text { Cumulative number } \\
\text { of side effects }\end{array}$ & $5.3(4.5)$ & $6.8(7.7)$ \\
\hline$P$ & \multicolumn{2}{|c|}{0.285} \\
\hline
\end{tabular}

${ }^{a}$ Analysis stratified by the two genotype groups.

$\mathrm{CYP}=$ CytochromeP450; NMs = normal metabolizers; $\mathrm{LMs}=$ lower metabolizers; HAM-D-17 = 17-item Hamilton Rating Scale for Depression.

\section{Combination Effects of 5-HT2A Receptor and CYP2D6 Gene Polymorphisms}

The above results indicated that both the A-1438G polymorphism of the 5-HT2A receptor gene and the CYP2D6 gene polymorphism had significant effects on the incidence of gastrointestinal side effects. Therefore, Cox regression was used to analyze the combination effect of the two polymorphisms on the gastrointestinal side effects. Figure 3 shows the combination effect of the 5-HT2A receptor and CYP2D6 gene polymorphisms on the incidence of the gastrointestinal side effects. The Cox regression analysis showed that LMs of CYP2D6 with the G/G genotype had a 4.242-fold higher risk of developing gastrointestinal side effects $(P=0.009)$ and LMs with the A/G genotype had a 4.147-fold higher risk of developing gastrointestinal side

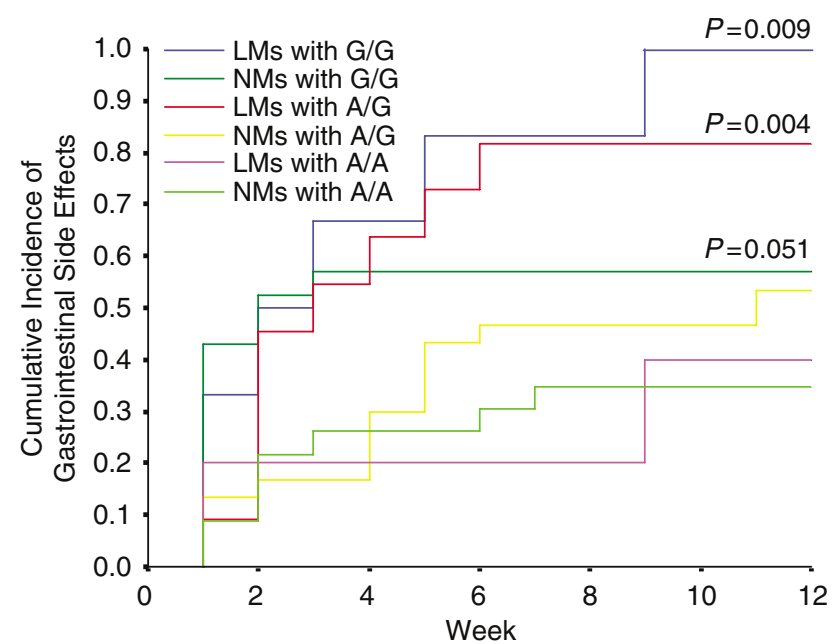

Figure 3 Combination effect of the A-1438G polymorphism of the 5-HT2A receptor gene and the CYP2D6 gene polymorphism on the cumulative 12-week incidence of gastrointestinal side effects induced by fluvoxamine.

Table 5 Combination Effect of the A- 1438G Polymorphism of the 5-HT2A Receptor and the CYP2D6 Phenotype

\begin{tabular}{|c|c|c|c|}
\hline & Hazard ratio & $95 \% \mathrm{Cl}$ & $P$ \\
\hline Sex & 0.65 & $0.368-1.146$ & 0.136 \\
\hline Age & 0.986 & $0.968-1.005$ & 0.148 \\
\hline Baseline HAM-D- 17 score & 1.045 & $0.988-1.106$ & 0.124 \\
\hline \multicolumn{4}{|c|}{ Combination of 5-HT2A and CYP2D6 polymorphisms } \\
\hline LMs with $A / A$ & 0.859 & $0.179-4.122$ & 0.849 \\
\hline NMs with $A / G$ & 1.681 & $0.717-3.939$ & 0.232 \\
\hline LMs with $A / G$ & 4.147 & $1.558-11.038$ & $0.004 *$ \\
\hline NMs with G/G & 2.491 & $0.997-6.223$ & 0.051 \\
\hline LMs with G/G & 4.242 & $1.444-12.459$ & $0.009 *$ \\
\hline
\end{tabular}

*Statistically significant.

5-HT = 5-hydroxytryptamine; CYP = CytochiomeP4SO; HAM-D- $17=17$-item Hamilton Rating Scale for Depression; NMs = normal metabolizers;

$\mathrm{LMs}=$ lower metabolizers.

effects $(P=0.004)$ than NMs with the A/A genotype (Table 5). NMs with the G/G genotype had a 2.491-fold higher risk of developing gastrointestinal side effects $(P=0.051)$ than NMs with the A/A genotype (Table 5). Sex, age, and baseline HAM-D-17 scores showed no significant effects on the risk of developing gastrointestinal side effects.

\section{DISCUSSION}

In this study of a Japanese sample population, it was first demonstrated that the A-1438G polymorphism of the 5-HT2A receptor gene might predict the incidence of gastrointestinal side effects induced by fluvoxamine in depressed patients. Murphy et al (2003) reported that discontinuation due to paroxetine-induced side effects was 
strongly associated with the C/C genotype of the 5-HT2A gene $\mathrm{T} 102 \mathrm{C}$ polymorphism, and that there was a significant linear relationship between the number of $\mathrm{C}$ alleles and the probability of discontinuation. Since T102C is in complete linkage disequilibrium with the A-1438G polymorphism, the results in Murphy et al (2003) are generally consistent with those reported in this study. However, there are some important differences between the results in the two studies. Although the probability of discontinuation due to any adverse events, including gastrointestinal side effects, differed significantly between the genotype groups in the former study, our results showed significant differences between the genotype groups for the incidence of gastrointestinal side effects, but not for the incidence of all side effects. Furthermore, the A-1438G polymorphism had no significant effect on discontinuation in this study. Our results may indicate that the A- $1438 \mathrm{G}$ polymorphism is only strongly related to the gastrointestinal side effects induced by fluvoxamine. While the subjects in the former study were 65 years of age or older, the mean age of the subjects in this study was $40.2 \pm 15.7$ years. Since elderly patients are thought to have pharmacodynamic and pharmacokinetic profiles different from those of younger patients, the difference in age may explain the discrepancy between the two studies. In addition, the difference in medication, paroxetine $v s$ fluvoxamine, may cause disagreement of the results, since the two SSRIs have been reported to have different pharmacodynamic and pharmacokinetic profiles (Bourin et al, 2001). On the contrary, Yoshida et al (2003) reported that the A-1438G polymorphism of the 5-HT2A gene had no significant effect on the incidence of nausea. Their results disagree with those presented in this study. This may result from differences between the two studies in the numbers of subjects and other methodological points such as the dosage schedules and periods of observation.

A postmortem brain study found that the $\mathrm{C}$ allele of $\mathrm{T} 102 \mathrm{C}$ (in complete linkage disequilibrium with the $\mathrm{G}$ allele of A-1438G) was associated with lower messenger ribonucleic acid (mRNA) and lower protein expression than the $\mathrm{T}$ allele (Polesskaya and Sokolov, 2002). Parsons et al (2004) reported that the presence of the A allele of A-1438G significantly increased promoter activity compared to the $\mathrm{G}$ allele. However, a study by Bray et al (2004) failed to replicate the differences in mRNA expression. Since the possible role of A-1438G in promoter function remains unclear, further studies are needed to clarify why this polymorphism affects the incidence of gastrointestinal side effects induced by fluvoxamine.

Moreover, sleep disturbances (Landolt et al, 1999) and sexual dysfunction (Sargent et al, 1998) are preferentially associated with the 5-HT2A receptor and it has been reported that SSRI-induced gastrointestinal side effects are mediated by the 5-HT3 receptor (Bergeron and Blier, 1994). To our knowledge, there have been no previous studies investigating the relationship between polymorphisms of the 5-HT3A and 3B genes and the gastrointestinal side effects induced by SSRI. In the current study, the polymorphisms of the 5-HT3A and 3B genes had no significant effects on the onset of fluvoxamine-induced gastrointestinal side effects. Tremblay et al (2003) reported that an insertion/deletion polymorphism in the promoter region of the 5-HT3B gene had a significant effect on the incidence of nausea and vomiting induced by cancer chemotherapy and that the Tyr129Ser polymorphism of the 5-HT3B gene, detected in this study, did not affect these side effects. On the other hand, Kaiser et al (2004) reported that polymorphisms of the 5-HT3A receptor gene may not serve as pharmacogenetic predictors of antiemetic treatment with 5-HT3 receptor antagonists in cancer patients. Since it is possible that polymorphisms of the 5-HT3A and 3B genes other than those detected in this study have significant effects on the gastrointestinal side effects, further studies are needed to clarify the impact of polymorphisms of the 5-HT3 gene on SSRI-induced gastrointestinal side effects.

Similar to A-1438G of the 5-HT2A receptor gene, the CYP2D6 polymorphism also showed a significant effect on the incidence of gastrointestinal side effects. Cox regression analysis showed that the combination of the A-1438G genotype and the CYP2D6 genotype could strongly predict the incidence of fluvoxamine-induced gastrointestinal side effects (Table 5). Indeed, there were six LMs of CYP2D6 who had the G/G genotype of the 5-HT2A receptor gene, and all of them suffered from gastrointestinal side effects. Among 11 LMs of CYP2D6 who had the A/G genotype, nine (81.8\%) suffered from gastrointestinal side effects. In clinical situations, taking account of these results, tailor-made pharmacotherapy for fluvoxamine based on genetic factors may be possible. For example, LMs with the G/G or A/G genotype should be treated by antidepressants other than SSRIs or should be treated at lower starting doses of fluvoxamine than the other patients. Kasper et al (1992) reported that an increased incidence of nausea is associated with higher plasma concentrations of fluvoxamine. Since it has been shown that the plasma concentrations of fluvoxamine depend on the CYP2D6 polymorphism, our results support the preceding study. However, Murphy et al (2003) reported that the CYP2D6 genotype did not influence the side effects from paroxetine. Gerstenberg et al (2003) also reported that the number of mutated CYP2D6 alleles was not related to the development of nausea induced by fluvoxamine. CYP2D6 gene polymorphisms are known to have ethnic differences; for example, the CYP2D $6 * 10$ allele, causing decreased enzyme activity, had a higher frequency in an Asian population (51\%) (Johansson et al, 1994) than in a white population (2.8\%) (Bertilsson and Dahl, 1996). These ethnic differences in the genetic polymorphisms may produce the discrepancy between the results in Murphy et al (2003) and those in the present study. However, similar to this study, the subjects in the study by Gerstenberg et al were all Japanese patients. In the former study, the patients were divided into three genotype groups by the number of CYP2D6 mutated alleles: ${ }^{\star} 1 /{ }^{\star} 1,{ }^{\star} 1 /{ }^{\star} 5$ or ${ }^{\star} 1 /{ }^{\star} 10$, and ${ }^{\star} 5 /{ }^{\star} 10$ or ${ }^{\star} 10 /{ }^{\star} 10$, whereas, in this study, the patients were divided into two genotype groups by the degree of enzyme activity: ${ }^{\star} 1 /{ }^{\star} 1$ or ${ }^{\star} 1 /{ }^{\star} 10$ and ${ }^{\star} 10 /{ }^{\star} 10,{ }^{\star} 1 /{ }^{\star} 5$ or ${ }^{\star} 5 /{ }^{\star} 10$. We previously reported that one $\star 5$ allele had a greater impact on the metabolism of haloperidol, a substrate of CYP2D6, than one ${ }^{\star} 10$ allele (Someya et al, 2003). Since ${ }^{\star} 1{ }^{\star} 10$ has only one mutation causing decreased enzyme activity, it was supposed that the enzyme activity of ${ }^{\star} 1{ }^{\star} 10$ was almost equal to that of the ${ }^{\star} 1 /{ }^{\star} 1$ genotype in this study. These differences in analysis may explain the inconsistency between the two studies. 
It was demonstrated that a pharmacodynamic factor such as the A-1438G polymorphism of the $5-\mathrm{HT} 2 \mathrm{~A}$ receptor gene and a pharmacokinetic factor such as the CYP2D6 gene polymorphism had synergistic effects on the prediction of the gastrointestinal side effects induced by fluvoxamine in Japanese depressed patients. However, since there have been several previous studies that were inconsistent with our results, much research remains to be carried out to explain the discrepancies.

\section{ACKNOWLEDGEMENTS}

This research was supported by Grants-in-Aid for Scientific Research (KAKENHI) from the Japan Society for the Promotion of Research (JSPS) (\#13670991 and \#13671000).

\section{REFERENCES}

Banes A, Florian JA, Watts SW (1999). Mechanisms of 5hydroxytryptamine(2A) receptor activation of the mitogenactivated protein kinase pathway in vascular smooth muscle. J Pharmacol Exp Ther 291: 1179-1187.

Bergeron R, Blier P (1994). Cisapride for the treatment of nausea produced by selective serotonin reuptake inhibitors. $\mathrm{Am} \mathrm{J}$ Psychiatry 151: 1084-1086.

Bertilsson L, Dahl ML (1996). Polymorphic drug oxidation. Relevance to the treatment of psychiatric disorders. CNS Drugs 5: 200-223.

Bourin M, Chue P, Guillon Y (2001). Paroxetine: a review. CNS Drug Rev 7: 25-47.

Bray NJ, Buckland PR, Hall H, Owen MJ, O'Donovan MC (2004). The serotonin-2A receptor gene locus does not contain common polymorphism affecting mRNA levels in adult brain. Mol Psychiatry 9: 109-114.

Erdmann J, Shimron-Abarbanell D, Rietschel M, Albus M, Maier $\mathrm{W}$, Korner J et al (1996). Systematic screening for mutations in the human serotonin-2A (5-HT2A) receptor gene: identification of two naturally occurring receptor variants and association analysis in schizophrenia. Hum Genet 97: 614-619.

Gerstenberg G, Aoshima T, Fukasawa T, Yoshida K, Takahashi H, Higuchi $\mathrm{H}$ et al (2003). Relationship between clinical effects of fluvoxamine and the steady-state plasma concentrations of fluvoxamine and its major metabolite fluvoxamino acid in Japanese depressed patients. Psychopharmacology (Berl) 167: 443-448.

Greenblatt DJ, von Moltke LL, Harmatz JS, Shader RI (1998). Drug interactions with newer antidepressants: role of human cytochromesP450. J Clin Psychiatry 59(Suppl 15): 19-27.

Hartter S, Wetzel H, Hammes E, Torkzadeh M, Hiemke C (1998). Serum concentrations of fluvoxamine and clinical effects. A prospective open clinical trial. Pharmacopsychiatry 31: 199-200. http://www.imm.ki.se/CYPalleles/.

Janssen P, Prins NH, Meulemans AL, Lefebvre RA (2002). Pharmacological characterization of the 5-HT receptors mediat- ing contraction and relaxation of canine isolated proximal stomach smooth muscle. Br J Pharmacol 136: 321-329.

Johansson I, Oscarson M, Yue Q, Bertilsson L, Sjöqvist F, Ingelman-Sundberg M (1994). Genetic analysis of the Chinese cytochrome P4502D6 locus: characterization of variant CYP2D6 genes present in subjects with diminished capacity for deberisoquine hydroxylation. Mol Pharmacol 46: 452-459.

Kaiser R, Tremblay PB, Sezer O, Possinger K, Roots I, Brockmoller $\mathrm{J}$ (2004). Investigation of the association between 5-HT3A receptor gene polymorphisms and efficiency of antiemetic treatment with 5-HT3 receptor antagonists. Pharmacogenetics 14: 271-278.

Kasper S, Fuger J, Moller HJ (1992). Comparative efficacy of antidepressants. Drugs 43(Suppl 2): 11-22; discussion 22-23.

Landolt HP, Meier V, Burgess HJ, Finelli LA, Cattelin F, Achermann $\mathrm{P}$ et al (1999). Serotonin-2 receptors and human sleep: effect of a selective antagonist on EEG power spectra. Neuropsychopharmacology 21: 455-466.

Murphy Jr GM, Kremer C, Rodrigues HE, Schatzberg AF (2003). Pharmacogenetics of antidepressant medication intolerance. $\mathrm{Am}$ J Psychiatry 160: 1830-1835.

Niesler B, Flohr T, Nothen MM, Fischer C, Rietschel M, Franzek E et al (2001). Association between the $5^{\prime}$ UTR variant C178T of the serotonin receptor gene HTR3A and bipolar affective disorder. Pharmacogenetics 11: 471-475.

Parsons MJ, D’Souza UM, Arranz MJ, Kerwin RW, Makoff AJ (2004). The $-1438 \mathrm{~A} / \mathrm{G}$ polymorphism in the 5-hydroxytryptamine type $2 \mathrm{~A}$ receptor gene affects promoter activity. Biol Psychiatry 56: 406-410.

Polesskaya OO, Sokolov BP (2002). Differential expression of the ' $\mathrm{C}$ ' and ' $\mathrm{T}$ ' alleles of the 5-HT2A receptor gene in the temporal cortex of normal individuals and schizophrenics. J Neurosci Res 67: $812-822$.

Sargent PA, Williamson DJ, Cowen PJ (1998). Brain 5-HT neurotransmission during paroxetine treatment. Br J Psychiatry 172: $49-52$.

Someya T, Shimoda K, Suzuki Y, Sato S, Kawashima Y, Hirokane G et al (2003). Effect of CYP2D6 genotypes on the metabolism of haloperidol in a Japanese psychiatric population. Neuropsychopharmacology 28: 1501-1505.

Steen VM, Andreassen OA, Daly AK, Tefre T, Borresen A-L, Idle JR et al (1995). Detection of the poor metabolizer-associated CYP2D6(D) gene deletion allele by long-PCR technology. Pharmacogenetics 5: 215-223.

Tremblay PB, Kaiser R, Sezer O, Rosler N, Schelenz C, Possinger K et al (2003). Variations in the 5-hydroxytryptamine type 3B receptor gene as predictors of the efficacy of antiemetic treatment in cancer patients. J Clin Oncol 21: 2147-2155.

Trindade E, Menon D, Topfer LA, Coloma C (1998). Adverse effects associated with selective serotonin reuptake inhibitors and tricyclic antidepressants: a meta-analysis. CMAJ 159: $1245-1252$.

Yoshida K, Naito S, Takahashi H, Sato K, Ito K, Kamata M et al (2003). Monoamine oxidase A gene polymorphism, 5-HT 2A receptor gene polymorphism and incidence of nausea induced by fluvoxamine. Neuropsychobiology 48: 10-13. 